\section{Analisis Desain Corrugated Steel Pipe sebagai konstruksi gorong-gorong pada sistem drainase PT. Krakatau Posco- Cilegon}

\section{Dwi Ratna Nur Farokha}

Staf Project Risk pada Subdit Management System \& Risk Management, Kantor Pusat PT. Pelabuhan Indonesia III (Persero).

dwi.farokha@pelindo.co.id
Seiring dengan perkembangan jaman dan teknologi, pekerjaan konstruksi tidak hanya mengacu pada biaya murah diawal, namun juga mempertimbangkan kepraktisan pelaksanaan serta kemudahan dalam pemeliharaan menjaga usia guna. Dalam sistem drainase, penggunaan Corrugated Steel Pipe (CSP) sebagai pengganti box culvert cukup efektif dalam mengatasi permasalahan rentang waktu pelaksanaan konstruksi, dan permasalahan terkait maintenance jangka panjangnya. Pada sistem drainase pelaksanaan proyek pembangunan PT. Krakatau Posco di Cilegon Banten, digunakan CSP sebagai konstruksi gorong gorong. Berdasarkan data kebutuhan penampang saluran, didapatkan dimensi pipa dari range $0,3 \mathrm{~m}$ sampai dengan 2,7 m. Pemeriksaan kekuatan struktur CSP terhadap beban kendaraan yang melalui di atasnya dilakukan dengan analisa perbandingan tegangan ultimate dengan tegangan ijin berdasarkan propertis penampang profil. Dari hasil analisa tersebut didapatkan bahwa ketebalan lapisan tanah urug di atas konstruksi sangat berpengaruh terhadap kekuatan dari konstruksi CSP.

Kata kunci: Corrugated steel pipe, drainase, box culvert, soil cover, PT. Krakatau Posco-Cilegon

Diajukan: 1 Juli 2019

Direvisi: 29 Juli 2019

Diterima: 29 Juli 2019

Dipublikasikan online: 30 Juli 2019

\section{Pendahuluan}

Pipa panjang bergelombang yang disebut juga Corrugated Steel Pipe(CSP) adalah dimana suatu pipa yang terbuat dari baja lembaran yang mengalami proses pembentukan gelombang (corrugating) dan pelengkungan (curving), dan dilapisi dengan Zink (galvanizing), yang antara lain digunakan untuk konstruksi gorong-gorong, saluran, terowongan, serta penutup atas conveyor (ARMTE, 2016).

Corrugated Steel Pipe atau dikenal dengan CSP terus mengembangkan perannya dalam teknologi rekayasa modern untuk sistem drainase. Struktur yang kuat namun fleksibel membuat semakin diminati baik diaplikasikan sebagai drainase maupun non-drainase. CSP tersedia dalam berbagai jenis lapisan sesuai dengan kebutuhan kondisi penggunaannya (lokasi maupun aplikasiannya).

Dalam project pembangunan kawasan pabrik baja PT. Krakatau Posco di Cilegon-Banten, direncanakan menggunakan sistem drainase terbuka pada area seluas $400 \mathrm{Ha}$. Dengan area yang sangat luas tersebut terdapat banyak cross section antara saluran dengan akses jalan di dalam kawasan pabrik. Adanya pertimbangan mengenai lintasan kendaraan berat (special heavy vehicle) dalam proses manufacture sehingga perlu konstruksi yang kuat namun mudah dalam proses pemeliharaan yang berkelanjutan, serta memiliki masa fungsi yang lama. Sehingga dibuat perencanaan konstruksi CSP sebagai gorong-gorong pada sistem drainase di kawasan manufacture PT. Krakatau Posco.

Berdasarkan data debit saluran drainase yang direncanakan ( $\mathrm{m}^{3} /$ detik), didapatkan range diameter CSP dari paling kecil yaitu $0,3 \mathrm{~m}$ hingga yang paling lebar yaitu $2,7 \mathrm{~m}$. Dalam optimalisasi biaya dan kemudahan pemasangan CSP, penentuan diameter dikelompokkan berdasarkan pendekatan kebutuhan luas penampung debit saluran.

Kontrol kekuatan struktur gorong-gorong menggunakan CSP dipengaruhi oleh beberapa hal utama yaitu diameter pipa, ketebalan pipa, dan tebal lapisan tanah di atas pipa yang dibahas secara detil dalam artikel ini.

\section{Metode}

Analisis kekuatan struktur CSP sebagai gorong-gorong pada sistem drainase PT. Krakatau Posco dihitung secara matematis menggunakan aplikasi Mathcad (PT. Krakatau Engineering, 2014). Beban yang digunakan dalam perhitungan struktur adalah beban as roda kendaraan (Axle load) sebesar 19,2 Ton.

Perhitungan dikelompokkan pada rentang diameter pipa 0,$3 ; 0,4 ; 0,5 ; 0,6 ; 0,7 ; 0,8 ; 0,9 ; 1,0 ; 1,1 ; 1,2 ; 1,3$; 1,$35 ; 1,4 ; 1,5 ; 1,6 ; 1,65 ; 1,7 ; 1,8 ; 1,9 ; 2,0 ; 2,2 ; 2,3 ; 2,4$; $2,7 \mathrm{~m}$.

Spesifikasi umum material dalam analisis struktur CSP meliputi:

Steel Construction : JIS g3101 SS-400

Cara mensitasi artikel ini:

Farokha, D.R.N (2019) Analisis desain corrugated steel pipe sebagai konstruksi gorong-gorong pada sistem drainase PT. Krakatau Posco - Cilegon. Buletin Profesi Insinyur 2(1) 041-044 


$\begin{array}{ll}\text { Steel Density } & : 7.850 \mathrm{t} / \mathrm{m}^{3} \\ \text { Elastic Modulus (E) } & : 200000 \mathrm{MPa} \\ \text { Poisson's Ratio } & : 0.3 \\ \text { Yield Strength (Fy) } & : 230 \mathrm{MPa} \\ \text { Tensile Strength } & : 370 \mathrm{MPa} \\ \text { Secant Modulus (Es) } & : 12 \mathrm{MPa}\end{array}$

\section{Analisis Kekuatan CSP}

Berdasarkan data perhitungan kebutuhan dimensi saluran, didapatkan tinggi soil cover $(\mathrm{H})$ yang dihitung dengan mempertimbangkan elevasi dasar saluran dan dimensi penampang gorong- gorong CSP (D) seperti terlihat pada Tabel 1.

Tabel 1 Data Dimensi Pipa dan Tebal Lapisan Tanah

\begin{tabular}{ccc|ccc}
\hline No. & $\begin{array}{c}\text { Diameter } \\
(\mathrm{m})\end{array}$ & $\begin{array}{c}\text { Soil } \\
\text { Cover } \\
(\mathrm{m})\end{array}$ & No. & $\begin{array}{c}\text { Diameter } \\
(\mathrm{m})\end{array}$ & $\begin{array}{c}\text { Soil } \\
\text { Cover } \\
(\mathrm{m})\end{array}$ \\
\hline 1 & 0,3 & 0,67 & 13 & 1,4 & 0,58 \\
2 & 0,4 & 0,57 & 14 & 1,5 & 0,45 \\
3 & 0,5 & 0,46 & 15 & 1,6 & 0,64 \\
4 & 0,6 & 0,35 & 16 & 1,65 & 0,55 \\
5 & 0,7 & 0,32 & 17 & 1,7 & 0,69 \\
6 & 0,8 & 0,30 & 18 & 1,8 & 0,47 \\
7 & 0,9 & 0,30 & 19 & 1,9 & 0,64 \\
8 & 1,0 & 0,45 & 20 & 2,0 & 0,59 \\
9 & 1,1 & 0,30 & 21 & 2,2 & 0,65 \\
10 & 1,2 & 0,56 & 22 & 2,3 & 0,61 \\
11 & 1,3 & 0,61 & 23 & 2,4 & 0,61 \\
12 & 1,35 & 0,48 & 24 & 2,7 & 0,75 \\
\hline
\end{tabular}

Untuk diameter pipa $\leq 1 \mathrm{~m}$ digunakan profile $68 \mathrm{x}$ 13 (Gambar 1), dan diameter $>1 \mathrm{~m}$ digunakan profile 76 x 25 (Gambar 2). Menentukan tebal CSP berdasarkan ketersediaan katalog, kemudian ditentukan section properties yaitu area penampang melintang CSP (A), momen inersia CSP (I) dan jari-jari lengkungan CSP $(r)$ (Tabel 2 dan Tabel 3).

Analisis Faktor Kuat Tekan akibat Beban Mati (TD) Berdasarkan NCSPA (National Corrugated Steel Pipe Association) (2008) perhitungan kuat tekan akibat beban mati adalah sebagai berikut :

$$
\begin{aligned}
& \mathrm{Cs}=\frac{E s \times D v}{E \times A} \\
& \mathrm{~W}=\left[\frac{(D v \cdot D h)-\left(\frac{1}{2} \cdot \pi \cdot D v \cdot D h\right)}{2}+H \cdot D v\right] \cdot \gamma \\
& \mathrm{TD}=0,5 \cdot[1-0,1 \cdot \mathrm{Cs}] . \mathrm{Af} \cdot \mathrm{W}(\mathrm{kN} / \mathrm{m})
\end{aligned}
$$

Dimana :

Dv $=$ Diameter vertikal $(\mathrm{m})$

$\mathrm{Dh}=$ Diameter horisontal $(\mathrm{m})$

$\gamma=$ berat volume tanah urugan $\mathrm{kg} / \mathrm{m}^{3}$

Af = faktor kelengkungan pipa (Gambar 3)

\section{Analisis Faktor Kuat Tekan Akibat Beban Hidup (TL)} Jika bidang kontak ban kendaraan adalah a (sisi memanjang jalan) dan b (sisi melintang jalan), maka didapatkan nilai TL dengan tahapan rumus berikut:

$$
\begin{aligned}
& \mathrm{l}_{i}=\mathrm{a}+2 . \mathrm{H} \\
& \mathrm{w}=\mathrm{b}+2 . \mathrm{H}
\end{aligned}
$$

$$
\begin{aligned}
\sigma \mathrm{L} & =\frac{\text { Axle load }}{\text { li } \mathrm{w}} \\
\mathrm{TL} & =0,5 . \mathrm{Dh} . \sigma \mathrm{L} . \mathrm{mf} \quad(\mathrm{kN} / \mathrm{m})
\end{aligned}
$$

Dimana :

$\mathrm{li}=$ distribusi kontak beban roda sisi memanjang jalan (m)

$\mathrm{w}=$ adalah distribusi kontak beban roda sisi melintang jalan (m)

Axle load = beban as roda $(\mathrm{kg})$

$\mathrm{mf}=$ koefisien beban kendaraan = 1,0 (NCSPA, 2008).

\section{Analisis Faktor Kuat Tekan Total (Tf)}

$$
\begin{aligned}
& \mathrm{DLA}=0,4-\left(0,2 \cdot \frac{\mathrm{H}}{\mathrm{m}^{\prime}}\right) \\
& \mathrm{Tf}=1,25 \cdot \mathrm{TD}+1,7 . \mathrm{TL} .(1+\mathrm{DLA}) \quad(\mathrm{kN} / \mathrm{m})
\end{aligned}
$$

dimana:

DLA = koefisien peredam beban hidup terdistribusi. Kombinasi faktor beban dalam kondisi ultimate atau ULS.

Tegangan Tekan Ultimate $\left(\sigma_{\text {ult }}\right)=\frac{T f}{A} \quad(\mathrm{MPa})$

Dimana:

$\mathrm{Tf}=$ kuat tekan ultimate $(\mathrm{kN} / \mathrm{m})$

$A=$ Luas area penampang profil $\left(\mathrm{m}^{2}\right)$

\section{Tegangan Izin Profil CSP $\left(\sigma_{\mathrm{ijin}}\right)$}

$\mathrm{H}^{\prime}=\frac{D v}{4}$

$\mathrm{R}=\mathrm{Rc}($ jari-jari CSP)

$\mathrm{Em}=\mathrm{Es} \cdot\left[1-\left(\frac{R c}{R c+H+H^{\prime}}\right)^{2}\right]$

$\lambda=1,22 \cdot\left[1,0+1,6\left(\frac{E \cdot I}{E m \cdot R c^{3}}\right)^{0,5}\right]$

$\mathrm{k}=\lambda \cdot\left(\frac{E \cdot I}{E m \cdot R c^{3}}\right)^{0,5}$

$\rho=\left(\frac{H+H^{\prime}}{R c}\right)^{0,5} \ldots \ldots \ldots \ldots . . . . j i k a ~ \rho>1$ maka diambil $\rho=1,0$

$\operatorname{Re}=\frac{r}{k} \cdot\left(\frac{6 \cdot E \cdot \rho}{F y}\right)^{0,5}$

$\mathrm{Fm}=1,0 \ldots \ldots$ faktor pengali untuk struktur tunggal $\emptyset_{\mathrm{t}}=0,8 \ldots \ldots \ldots \ldots . . .$. untuk $\mathrm{R} \leq \mathrm{Re}$

Sehingga :

$\sigma_{\mathrm{ijin}}=\emptyset_{\mathrm{t}} . \mathrm{Fm} .\left[\mathrm{Fy}-\frac{(F y \cdot k \cdot R)^{2}}{12 \cdot E \cdot r^{2} \cdot \rho}\right]$.

maka struktur dinyatakan aman jika $\sigma_{\mathrm{ult}}<\sigma_{\mathrm{ijin}}$ (NCSPA, 2008)

Jika $\sigma_{\mathrm{ult}}>\sigma_{\mathrm{ijin}}$, maka dilakukan perhitungan ulang dari awal dengan merubah diameter CSP menjadi lebih kecil dan menambah tebal soil cover. Dalam menentukan diameter CSP harus tetap memperhatikan debit air pada saluran terkait. Untuk saluran dengan debit air yang tinggi sehingga membutuhkan diameter CSP yang lebar, dapat digantikan dengan CSP berdiameter lebih kecil dengan jumlah yang lebih banyak.

\section{Hasil Analisis}

Berdasarkan analisis terhadap semua profil CSP, didapatkan data yang dirangkum pada Tabel 4. Dengan perbandingan $\sigma_{\mathrm{ult}}<\sigma_{\mathrm{ijin}}$, didapatkan bahwa konstruksi, dengan kombinasi diameter dan tebal soil cover yang ditentukan, dalam kondisi aman. Adapun pada kondisi tertentu diperlukan penurunan elevasi untuk mendapatkan tebal soil cover yang optimal dengan diameter yang mampu menampung debit saluran pada titik yang bersangkutan (yaitu pada kondisi No. 12, 14, $18,20,21,22,23$, dan 24). 


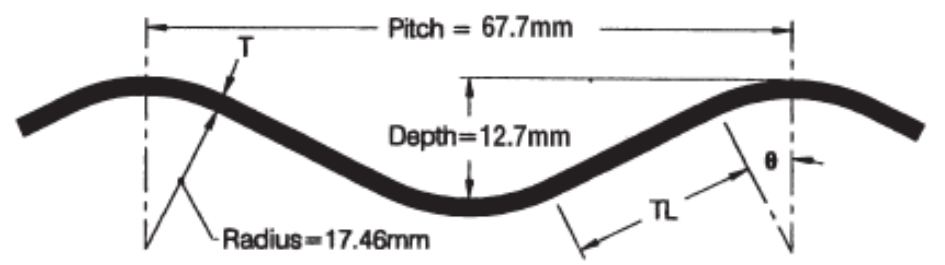

Gambar 1. Profil CSP $68 \times 13 \mathrm{~mm}$

Tabel 2 Propertis Profil CSP 68 x 13 mm (True North Steel, 2017)

\begin{tabular}{|c|c|c|c|c|c|c|c|c|}
\hline \multicolumn{2}{|c|}{ Wall Thickness } & \multirow[b]{2}{*}{ Area } & \multirow{2}{*}{$\begin{array}{l}\text { Tangent } \\
\text { Length }\end{array}$} & \multirow{2}{*}{$\begin{array}{l}\text { Tangent } \\
\text { Angle }\end{array}$} & \multirow{2}{*}{$\begin{array}{l}\text { Moment } \\
\text { of Inertia }\end{array}$} & \multirow{2}{*}{$\begin{array}{l}\text { Section } \\
\text { Modulus }\end{array}$} & \multirow{2}{*}{$\begin{array}{l}\text { Radius of } \\
\text { Gyration }\end{array}$} & \multirow{2}{*}{$\begin{array}{l}\text { Developed } \\
\text { Whdth } \\
\text { Factor }\end{array}$} \\
\hline Specifiled & Design & & & & & & & \\
\hline$T$ & $T$ & A & TL & $\theta$ & 1 & s & $\mathbf{r}$ & WF \\
\hline $\mathrm{mm}$ & $\mathrm{mm}$ & $\mathrm{mm}^{2} / \mathrm{mm}$ & $\mathrm{mm}$ & Degrees & $\mathrm{mm} / \mathrm{mm}$ & $\mathrm{mm}^{3} / \mathrm{mm}$ & $\mathrm{mm}$ & $*$ \\
\hline 1.3 & 1.120 & 1209 & 19.759 & 26.647 & 2261 & 3.27 & 4.324 & 1.079 \\
\hline 1.6 & 1.400 & 1.512 & 19.578 & 26.734 & 28.37 & 4.02 & 4.332 & 1.080 \\
\hline 2.0 & 1.820 & 1.966 & 19.304 & 28.867 & 37.11 & 5.11 & 4.345 & 1.080 \\
\hline 2.8 & 2.640 & 2.852 & 18.765 & 27.136 & 54.57 & 7.11 & 4.374 & 1.080 \\
\hline 3.5 & 3.350 & 3.621 & 18.269 & 27.381 & 70.16 & 8.74 & 4.402 & 1.081 \\
\hline 42 & 4.080 & 4.411 & 17.755 & 27.643 & 86.71 & 10.33 & 4.433 & 1.081 \\
\hline
\end{tabular}

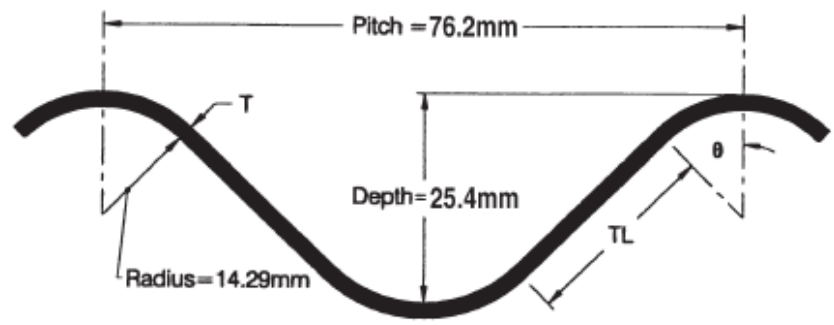

Gambar 2. Profil 76 × 25 mm

Tabel 3 Propertis Profil CSP 76 × 25 mm (True North Steel, 2017)

\begin{tabular}{|c|c|c|c|c|c|c|c|c|}
\hline \multicolumn{2}{|c|}{ Wall Thickness } & \multirow[b]{2}{*}{ Area } & \multirow{2}{*}{$\begin{array}{l}\text { Tangent } \\
\text { Length }\end{array}$} & \multirow{2}{*}{$\begin{array}{c}\text { Tangent } \\
\text { Angle }\end{array}$} & \multirow{2}{*}{$\begin{array}{l}\text { Moment } \\
\text { of Inertla }\end{array}$} & \multirow{2}{*}{$\begin{array}{l}\text { Section } \\
\text { Modulus }\end{array}$} & \multirow{2}{*}{$\begin{array}{l}\text { Radlus of } \\
\text { Gyration }\end{array}$} & \multirow{2}{*}{$\begin{array}{c}\text { Developed } \\
\text { Width } \\
\text { Factor }\end{array}$} \\
\hline Specified & Design & & & & & & & \\
\hline$T$ & $T$ & A & $\mathrm{TL}$ & $\theta$ & I & s & $\mathbf{r}$ & WF \\
\hline $\mathrm{mm}$ & mm & $\mathrm{mm} 2 / \mathrm{mm}$ & $\mathrm{mm}$ & Degrees & $\mathrm{mm}^{4} / \mathrm{mm}$ & $\mathrm{mm}^{3} / \mathrm{mm}$ & $\mathrm{mm}$ & $*$ \\
\hline 1.3 & 1.12 & 1.389 & 24.159 & 44.389 & 103.96 & 7.84 & 8.653 & 1240 \\
\hline 1.6 & 1.40 & 1.736 & 23.862 & 44.580 & 130.40 & 9.73 & 8.666 & 1240 \\
\hline 2.0 & 1.82 & 2259 & 23.411 & 44.875 & 170.40 & 12.52 & 8.685 & 1241 \\
\hline 2.8 & 2.64 & 3281 & 22.504 & 45.479 & 249.73 & 17.81 & 8.724 & 1243 \\
\hline 3.5 & 3.35 & 4.169 & 21.688 & 46.035 & 319.77 & 22.24 & 8.758 & 1244 \\
\hline 42 & 4.08 & 5.084 & 20.815 & 46.645 & 393.12 & 26.67 & 8.794 & 1246 \\
\hline
\end{tabular}

\section{Kesimpulan}

Dari hasil analisis dapat disimpulkan beberapa hal yaitu:

1. CSP dapat digunakan sebagai alternatif konstruksi pada sistem drainase yang mampu melayani beban kerja yang direncanakan

2. Penggunaan CSP sebagai alternatif sangat efektif dalam pelaksanaanya, karena kekuatan struktur hanya dipengaruhi oleh ketebalan soil cover di atasnya, tanpa perlu perkuatan struktur pada lapisan di atasnya.
3. Ketebalan lapisan tanah urug di atas struktur CSP sangat mempengaruhi kekuatan dari CSP tersebut, dimana ketebalan minimumnya relatif kecil yaitu $30 \mathrm{~cm}$ untuk diameter CSP 0,3-2 m dan ketebalan $45 \mathrm{~cm}$ untuk diameter CSP 2,5-3 m.

4. Semakin besar diameter CSP maka kebutuhan tebal lapisan tanah urug di atasnya juga semakin tinggi.

5. Jika kontrol tegangan struktur tidak memenuhi syarat, dapat dilakukan re-desain dengan mempertebal lapisan tanah urug (soil cover) atau dengan mempertebal profil CSP. 


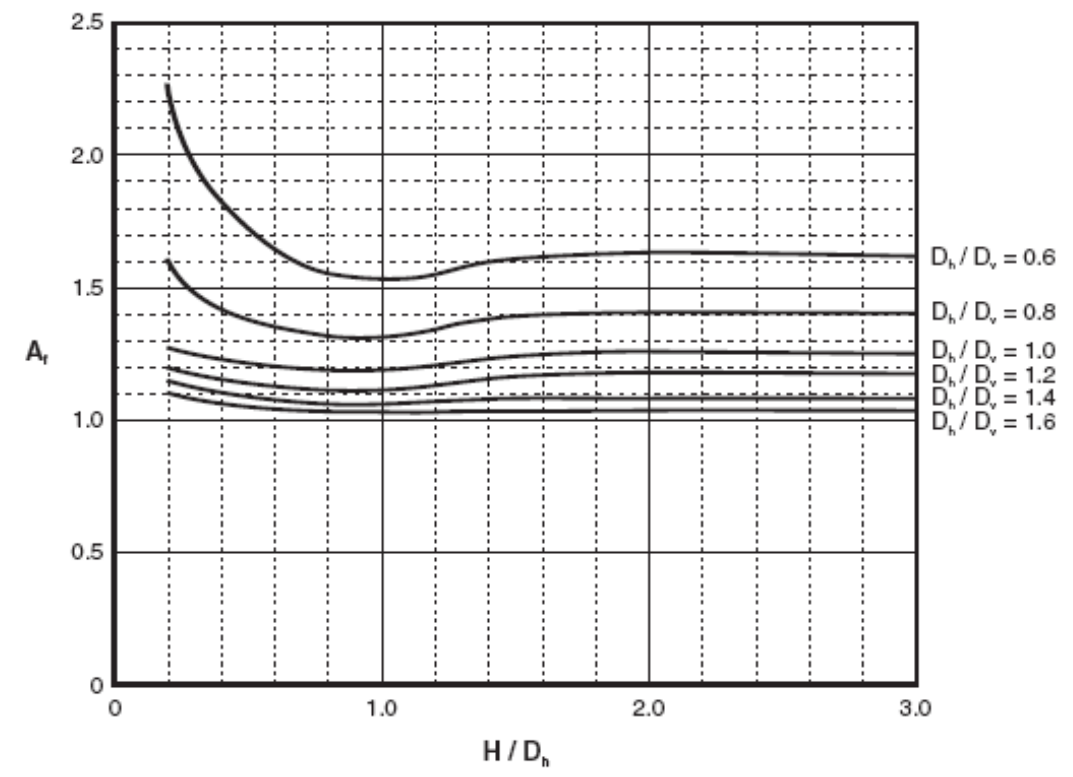

Gambar 3 Grafik faktor kelengkungan pipa (Af)

Tabel 4 Hasil pengecekan terhadap semua dimensi CSP dengan tebal urugan terkecil

\begin{tabular}{cccccl}
\hline No. & $\begin{array}{c}\text { Diameter } \\
(\mathrm{m})\end{array}$ & $\begin{array}{c}\text { Soil Cover } \\
(\mathrm{m})\end{array}$ & $\begin{array}{c}\sigma_{\mathrm{ult}} \\
(\mathrm{MPa})\end{array}$ & $\begin{array}{c}\sigma_{\mathrm{ijin}} \\
(\mathrm{MPa})\end{array}$ & \\
\hline $\mathbf{1}$ & 0,3 & 0,67 & 36,628 & 181,324 & Ok \\
$\mathbf{2}$ & 0,4 & 0,57 & 14,74 & 166,1 & Ok \\
$\mathbf{3}$ & 0,5 & 0,46 & 19,77 & 129,84 & Ok \\
$\mathbf{4}$ & 0,6 & 0,35 & 30,12 & 128,629 & Ok \\
$\mathbf{5}$ & 0,7 & 0,32 & 37,59 & 127,83 & Ok \\
$\mathbf{6}$ & 0,8 & 0,30 & 45,019 & 126,909 & Ok \\
$\mathbf{7}$ & 0,9 & 0,30 & 45,5 & 126,046 & Ok \\
$\mathbf{8}$ & 1,0 & 0,45 & 43,895 & 131,269 & Ok \\
$\mathbf{9}$ & 1,1 & 0,30 & 42,046 & 144,059 & Ok \\
$\mathbf{1 0}$ & 1,2 & 0,56 & 38,4 & 145,26 & Ok \\
$\mathbf{1 1}$ & 1,3 & 0,61 & 31,228 & 143,308 & Ok \\
$\mathbf{1 2}$ & 1,35 & 0,48 & 42,528 & 141,463 & Ok dengan penurunan elevasi \\
$\mathbf{1 3}$ & 1,4 & 0,58 & 42,377 & 141,415 & Ok \\
$\mathbf{1 4}$ & 1,5 & 0,45 & 43,778 & 138,859 & Ok dengan penurunan elevasi \\
$\mathbf{1 5}$ & 1,6 & 0,64 & 44,119 & 138,959 & Ok \\
$\mathbf{1 6}$ & 1,65 & 0,55 & 44,909 & 143,812 & Ok \\
$\mathbf{1 7}$ & 1,7 & 0,69 & 45,575 & 138,00 & Ok \\
$\mathbf{1 8}$ & 1,8 & 0,47 & 33,122 & 125,84 & Ok dengan penurunan elevasi \\
$\mathbf{1 9}$ & 1,9 & 0,64 & 34,06 & 126,382 & Ok \\
$\mathbf{2 0}$ & 2,0 & 0,59 & 34,662 & 124,628 & Ok dengan penurunan elevasi \\
$\mathbf{2 1}$ & 2,2 & 0,65 & 36,432 & 123,623 & Ok dengan penurunan elevasi \\
$\mathbf{2 2}$ & 2,3 & 0,61 & 37,059 & 122,508 & Ok dengan penurunan elevasi \\
$\mathbf{2 3}$ & 2,4 & 0,61 & 37,855 & 121,672 & Ok dengan penurunan elevasi \\
$\mathbf{2 4}$ & 2,7 & 0,75 & 41,545 & 120,456 & Ok dengan penurunan elevasi \\
\hline & & & & & \\
\hline
\end{tabular}

\section{Ucapan Terimakasih}

Ucapan terimakasih kepada PT. Pelabuhan Indonesia III (Persero) sebagai sponsor dalam mengikuti Program Profesi Insinyur di Universitas Lambung Mangkurat.

\section{Referensi}

ARMTE (2016) Corrugated Steel Pipe Effective and durable drainage solution.
NCSPA (2008) Corrugated Steel Pipe Design Manual First Edition. National Corrugated Steel Pipe Association, Dallas.

PT. Krakatau Engineering (2014) Calculation Of Corrugated Steel Pipe All (1st, 2nd, 3rd, Last Order \& Additional Work) Revisi 1. Cilegon.

True North Steel (2017) Corrugated Steel Pipe Technical Specification Guide. 